\section{New SSC members}

PAGES is pleased to introduce three new members of its Scientific Steering Committee (SSC). Collectively they will strengthen the committee's modeling and sea level expertise.

Pascale Braconnot from heads the Climate Modeling team at Laboratoire des Sciences du Climat et de I'Environnement in Gifsur-Yvette, France. Her scientific interest con-

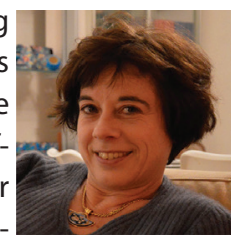
cerns the role of the ocean in climate and changes in the tropical hydrological cycle, focusing on the Afro-Asian monsoon and the El Niño-Southern Oscillation.

Hugues Goosse is a climate modeler at the Université catholique de

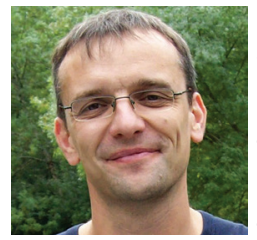
Louvain in Belgium, with a strong interest in decadal to multi-centennial climate variability and on the application of data assimilation methods in paleoclimatology.

Yusuke Yokoyama is Associate Professor at the Atmosphere and Ocean Research Institute of the University of Tokyo, Japan. His research is on proxybased sea-level change and the development of dating methods to interpret sea-level and other palaeoclimate records.

We'd like to take this opportunity to thank the members who recently rotated off the SSC, Takeshi Nakatsuka, Pierre Francus and José Carriquiri, for their invaluable support and contributions during their time on the PAGES SSC.

\section{Goa meetings}

The $4^{\text {th }}$ PAGES Open Science Meeting (OSM) and $2^{\text {nd }}$ Young Scientists Meeting (YSM), which were held in February 2013 in Goa, India, fostered scientific exchange and collaboration amongst participants from around the world. If you weren't amongst those attending, you may still participate retrospectively in the events: View sessions and abstracts on the website, and stay tuned for presentation, poster, photo and video uploads (www.pages-osm.org).

\section{PAGES umbrella programs}

In April, PAGES, the Forum for Climate and Global Change ProClim, and the Oeschger Centre for Climate Change Research, will jointly host the annual meeting of the Scientific Committee of the International Geosphere-Biosphere Programme in Bern, Switzerland. The dominating topic will be the shaping of and transitioning to the Future Earth super-program (see Program
News, PAGES news 20(2)), which may become the "next big thing" in terms of Global Change science organization.

\section{Support for meetings}

During its meeting in February, the PAGES SSC granted support for a total of nine scientific and educational meetings. The next deadline for applying for PAGES meeting support is 1 May 2013. Support can be sought for workshop-style meetings relevant to PAGES Foci and Cross Cutting Themes. The three eligible categories are PAGES Working Group meetings, workshops with a design towards training or education, and an open call for other PAGES-relevant workshops. Application guidelines and forms can be found on the PAGES website (My PAGES > Meeting Support).

\section{Next newsletter issues}

The next two issues of PAGESnews will focus on ENSO and Dust. While the ENSO issue is closed, suitable articles for the Dust issue may still be included. Contact Ute Merkel (umerkel@marum.de) before 30 April 2013. As always, you are invited to submit Science Highlights, Program News, and Workshop Reports for the Open Section of PAGESnews. Find author guidelines on the PAGES website (My PAGES $>$ Newsletter).

\title{
Editorial: Past4Future - learning from interglacials
}

The EU Framework Programme 7 Collaborative Project Past4Future aims to generate knowledge from climate change during past interglacials that can improve our ability to predict the future.

\section{Dorthe Dahl-Jensen ${ }^{1}$, Emilie Capron ${ }^{2}$ and Emma Stone ${ }^{3}$}

${ }^{1}$ Centre for Ice and Climate, Niels Bohrs Institute, University of Copenhagen, Denmark; ddj@gfy.ku.dk ${ }^{2}$ British Antarctic Survey, Cambridge, UK; ${ }^{3}$ School of Geographical Sciences, University of Bristol, UK

lobal warming strongly influences the future prospects of both citizens and policy makers. The change of climate calls for innovative decisions on food production, risk management, and energy policy. Uncertainties concerning the interplay between natural climatic and environmental variations and man-made changes remain a major obstacle for defining plausible trajectories of climate change in the coming decades. This is important for decisions on mitigation, adaptation, and risk reduction and our capability to monitor the efficiency of climate policy frameworks to reach desired climate targets.

By studying past climate changes when the Earth was as warm or warmer than at present we can gain knowledge about natural climatic and environmental variability on decadal to multi-millennial timescales and relate them to the recent changes originating from anthropogenic influences.
Paleorecords show that the climate system has changed abruptly in the past (e.g. Alley et al. 1997; Dansgaard et al. 1993; Steffensen et al. 2008), but the extent of such changes during warm periods has still to be fully investigated. Understanding the climate dynamics and variability during warm time periods, and the likelihood of abrupt changes within the system, requires improved insight into interactions between forcings such as freshwater 
discharge, changes in solar irradiance, volcanic eruptions and greenhouse gas concentration, and sensitive components of the climate system such as monsoon patterns, thermohaline circulation, sea ice extent, and ice sheets (IPCC AR4 report 2007).

In this context, "Past4Future", a Collaborative Project launched in January 2010 under the $7^{\text {th }}$ Framework Programme of the European Commission, aims at improving our understanding of the processes involved in the climatic variations over the last two interglacial periods. PAGES is a project partner charged with project outreach through the PAGES newsletter and a website. Moreover, Past4Future science is internationally interwoven with several PAGES activities, such as the PAGES working groups on sea level (PALSEA), past interglacials (PIGS), paleofire (GPWG), and sea ice (SIP). This special issue of the PAGES newsletter is accordingly sponsored by Past4Future. It illustrates the research undertaken until now in the framework of the project and reports about recent PAGES related activities.

\section{The Past4Future project}

The Past4Future project uses existing and new paleoclimate records from ice cores (e.g. Dahl-Jensen et al.; Masson-Delmotte et al. this issue), marine cores (e.g. Gersonde and de Vernal; Andresen et al. this issue), speleothems (e.g. Genty et al. this issue), and pollen amongst others. Combining the globally distributed records from these archives enables us to reconstruct climatic and environmental changes during the present interglacial (the Holocene) and the last interglacial (hereafter, LIG). In addition to providing the highest resolved and most comprehensive datasets available for studying past interglacials, these two time periods constitute distinct case studies to explore climate feedbacks in response to orbital forcing. The LIG also appears to be exceptionally warm in the context of the past 800 ka (e.g. Jouzel et al. 2007; Lang and Wolff 2011; NEEM community members 2013). As a consequence, it provides insights for future climate change driven by anthropogenic greenhouse gas emissions (e.g. Otto-Bliesner et al. 2006; Turney and Jones 2010). The paleoclimatic records are combined in integrated analyses with climate models of various degrees of complexity (Stone et al. this issue a), proxy modeling (Sime et al. this issue) and data assimilation (Mairesse et al. this issue).

As such, the Past4Future project is focused around the following four key questions:

\section{What is the risk of abrupt changes in interglacials?}

Abrupt changes during interglacials are caused by poorly understood complex interactions of internal and external forcings. Investigation of the forcings, reaction of the climate system, and impacts on the environment are carried out through integration of synchronized observations and model output. Results aim to inform on the risk of abrupt changes in the next century when man-made forcings such as increasing greenhouse gases add a dimension to the complexity of the system (Sapart et al. 2012).

\section{Can we understand the greenhouse gas records of the interglacial periods?}

On orbital timescales greenhouse gases mirror climate changes with lower concentrations in cold periods and higher concentrations in warmer periods (e.g. Lüthi et al. 2008). Studying greenhouse gas changes across past interglacials offers insights into the dynamics of greenhouse gas budgets and fluxes, e.g. through variations in the capacity of the ocean and terrestrial biosphere to absorb atmospheric $\mathrm{CO}_{2}$, and the possibility of methane release in response to warming. Understanding the biogeochemical cycle in the past is therefore crucial for predicting the future (see Brücher and Brovkin, this issue).

\section{What is the risk of rapid collapse of polar ice sheets?}

Sea level changes are one serious risk that strongly influences the living conditions for the large populations in close proximity to the sea (e.g. Bangladesh). The IPCC Fourth Assessment Report (AR4) estimates a sea level rise between 18 and $59 \mathrm{~cm}$ by the year 2100 . This estimate range, however, did not include the full effect of possible changes in ice sheet dynamics. Therefore, the AR4 probably underestimates the upper bound for sea level rise. The LIG has experienced sea level highstands several meters above today (Kopp et al. 2009; Dutton and Lambeck 2012) attributed, in part, to a reduction in ice sheet volume in both polar regions. Thus studying the LIG can advance our ability to predict reaction times and thresholds for the ice sheets (Siddall et al.; Masson Delmotte et al. this issue).

\section{Did ocean circulation change significantly during previous interglacials?}

Ocean circulation strongly influences the climate of Europe, especially through the warm surface currents in the North Atlantic Ocean (e.g. Jacob et al. 2005). During glacial periods the ocean circulation has abruptly changed resulting in dramatic climate changes. The interglacial periods offer an opportunity to see to what degree shutdowns or slowdowns of the thermohaline circulation occurred in previous warm periods (e.g. Bakker et al. 2012; Govin et al. 2012).

The content of this PAGES newsletter strongly reflects the cross-disciplinary nature of the Past4Future work packages which focus both on data and modeling targets. The newsletter begins by giving a flavor of how to collect paleodata in the field including the logistics and challenges involved (Genty et al.; Gersonde and Seidenkrantz; Steffensen et al. this issue). In addition, it highlights the challenges encountered by the climate modelers in the computer lab (Stone et al. this issue b). The Science Highlights report on a diverse range of topics: reviews of previous research (e.g. Capron et al. this issue), collaborative modeling efforts, new methodological approaches (e.g. Kerhwald et al. this issue), data compilation etc. Indeed, one product of the Past4Future project, aside from new research results, is the integration of the different research groups to successfully address the challenge of model-data comparison.

The Past4Future project is ongoing until 2015. The results are already significant but they also show the challenges ahead in providing a coherent story of climate interactions in the past and how this might be used to inform on future climate.

\section{Selected references}

Full reference list online under:

http://www.pages-igbp.org/products/newsletters/ref2013_1.pdf

\section{Alley RB et al. (1997) Geology 25: 483-486}

Bakker P, Van Meerbeeck CJ, Renssen (2012) Climate of the Past 8: $995-$ 1009

Govin A et al. (2012) Climate of the Past 8: 483-507

Lang N, WolffEW (2011) Climate of the Past 7, 361-380

Turney CSM, Jones RT (2010) Journal of Quaternary Science 25: 839-843 